\title{
Analysis of diurnal activity patterns and related changes in metabolism in the cephalopod Sepia officinalis
}

Gilta Jäckel ${ }^{1}$, Felix C. Mark², Magdalena Gutowska1 , Guy Claireaux, Charlie Ellington ${ }^{2}$ \& Hans O. Pörtner1

Denton and Gilpin-Brown hypothesized in 1961 that the cuttlefish Sepia officinalis displays diurnal changes in activity levels. Other cephalopods perform a diurnal pattern as well (Wells et al 1983, Meisel et al 2003).

We therefore analysed activity patterns of S. officinalis using digital video recordings and analysis. We monitored S. officinalis activity by video continuously for 5 days. In a parallel experiment, we measured oxygen consumption rates in order to see whether metabolic rate changes in parallel with activity levels. We compared both parameters to check the hypothesis of Denton on the one hand and to see how strongly diurnal rhythms influence metabolic rate on the other hand. Values for SMR and AMR estimated from activities and $\mathrm{MO}_{2}$ of both fed and unfed animals depict the influence of food availability and light on diurnal activity patterns of Sepia officinalis.

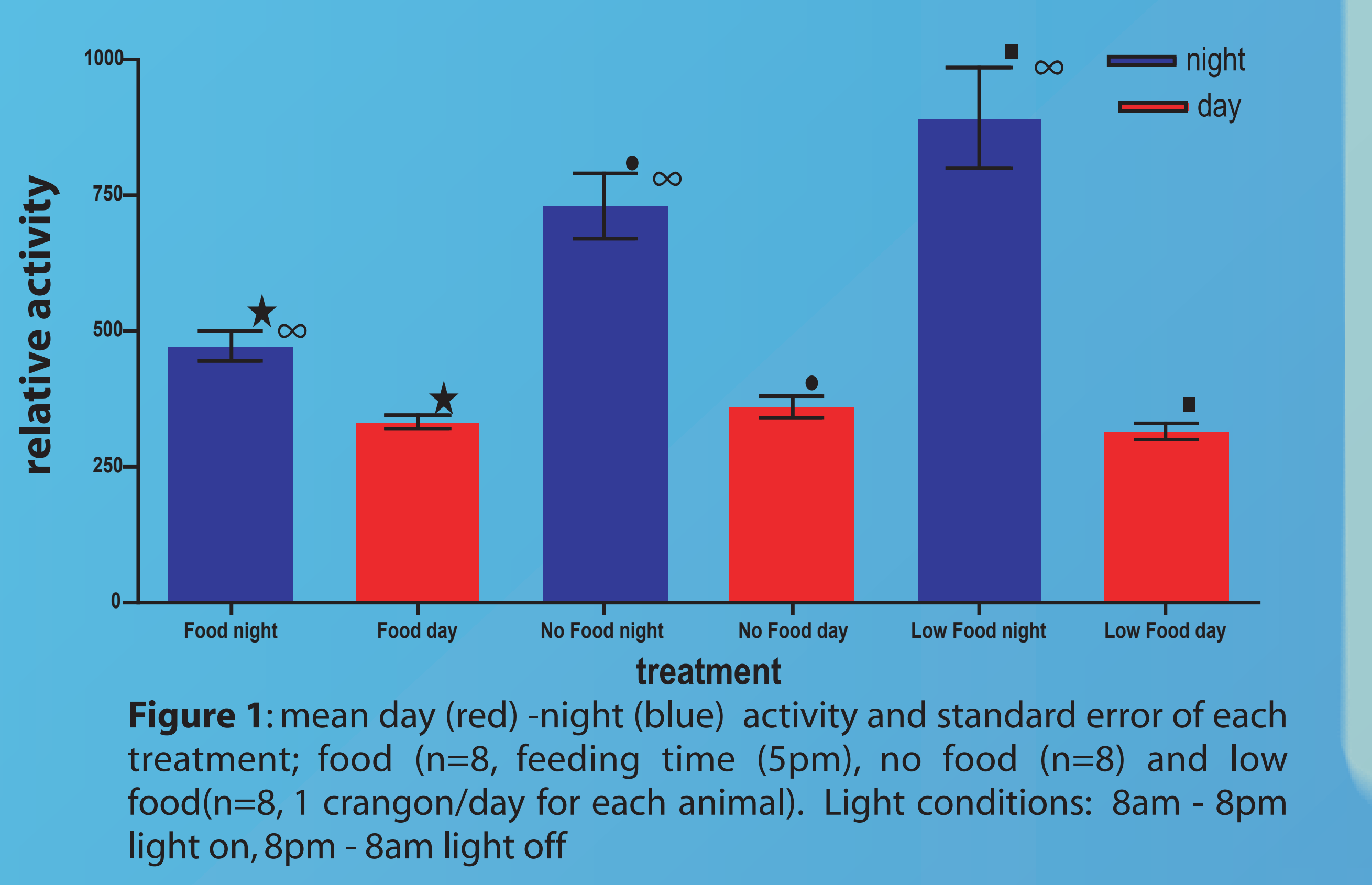

\section{Activity}

clear day-night pattern within each treatment

- day activity does not differ between the treatments, but

- night activity without feeding is nearly twice as large as without feeding (fig. 1)

- both treatments show a response to light-on- and light-off-effect (fig. 2)$$
\text { - no similar decreases in oxygen consumption and activity curves }
$$
animal at night (fig. 3) (fig. 4)

\section{Oxygen consumption}

- clear day-night pattern for each

- 30-40\% rise in oxygen consumption

- strong response to light-off-effect

- SMR $=4,667 \mu \mathrm{mol} \mathrm{O}_{2} * \mathrm{~h}^{-1 *} \mathrm{~g}^{-1} \mathrm{Fw} \pm 0,055$ $\mathrm{AMR}=6,094 \mu \mathrm{mol} \mathrm{O} 2 * \mathrm{~h}^{-1} \mathrm{~g}^{-1} \mathrm{Fw} \pm 0,097$
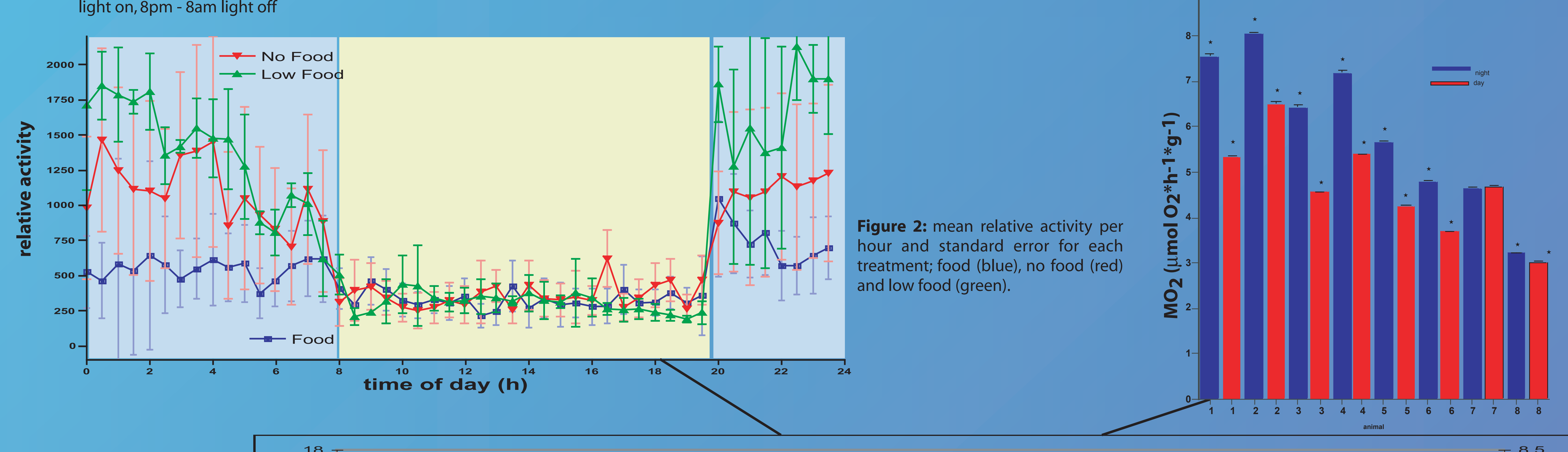

Figure 3: mean day (red) - night (blue) oxygen consumption
$\left(\mathrm{MO}_{2}\right)$ and standard error for each animal $(n=8)$, oxygen consumption was measured continuously over $3-5$ days.
Light conditions: 8 am $-8 p m$
light on, $8 \mathrm{pm}-8 \mathrm{pm}$ light off Light conditions: 8 am $-8 \mathrm{p}$
light on, $8 \mathrm{pm}-$ - 8am light off

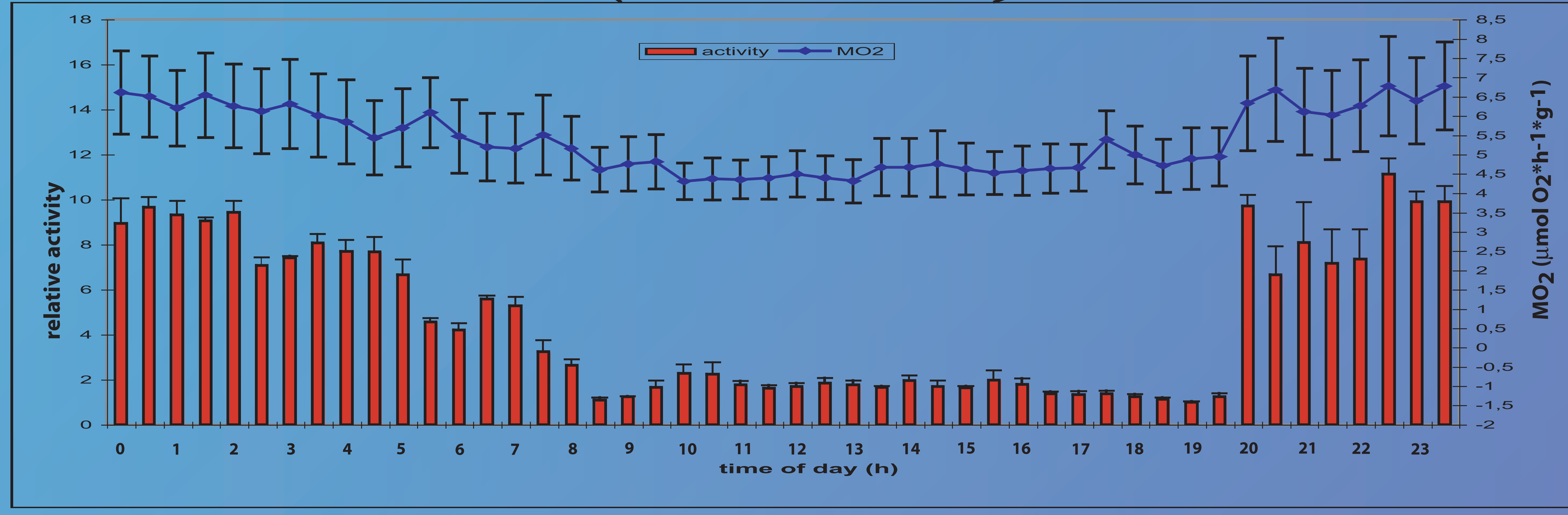

Figure 4: Comparison of oxygen consumption and relative activity of starved Sepia officinalis over 24h; mean activity (red) with standard error and mean oxygen consumption

\section{Conclusion}

- starved Sepia officinalis display a clear diurnal activity pattern. This pattern is also visible in the oxygen consumption, which has already been shown for the cephalopod Octopus vulgaris (Wells et al. 1983)

feeding in the evening does not influence day-time activity, which is similar to the findings of Wells et al. 1983, too, but it increases night-time activity

activity depends on light conditions and especially the sunset (light-off-effect) has an important role as "zeitgeber", which differs from O. vulgaris (Meisel et al.2003) and support the hypothesis that S.officinalis are twilight-feeders

activity and oxygen consumption do not decrease in parallel, therefore other metabolic processes may be influenced by the diurnal pattern as well, e.g. enzyme activities 